\title{
The Human Element Of Project Management
}

\author{
Sharlett Gillard, University of Southern Indiana, USA
}

\begin{abstract}
Much research and dialogue have been published about project management. Studies have been conducted regarding the impact of size, member location, gender composition, cross-functional structure, stakeholder influence, confidence issues, technology usage, management style, generational differences, technical expertise vs. people skills, and a myriad of other topics. Writings regarding the human factors, the "soft" skills, have typically focused on the "what is" and "why" elements of communication and conduct appropriate to project management, often leaving the "how to" in subjection or missing. This article provides additional practical applications to improve project management success.
\end{abstract}

Keywords: Project Management; Human Communication; Soft Skills

\section{INTRODUCTION}

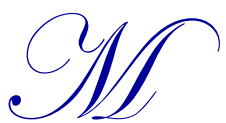

uch research and dialogue have been published about project management since the Department of Defense popularized it in the early 1970s (Kerzner, 2001/2009). Studies have been conducted regarding the impact of size, member location, gender composition, cross-functional structure, stakeholder influence, confidence issues, technology usage, management style, generational differences, technical expertise vs. people skills, and a myriad of other topics. Writings regarding the human factor, the "soft" skills of project management, have typically focused on communication as either a skill or as a factor of success (Ziek \& Anderson, 2015). Whereas the insights gleaned are valuable and may foster improvement in both efficiency and effectiveness, the "how to" often seems to be in subjection or missing in favor of the "what is" and "why" elements of project management. This article provides additional practical applications to improve project management success.

According to Henderson and Stackman (2010), project teams working on projects of $\$ 1$ million or less tend to be physically "co-located" and "more reliant on face-to-face communication"; whereas projects with larger budgets tend to be more geographically distributed and more dependent on technology to communicate. But while there may be a lack of face-to-face communication in distributed teams, (Morgan, Paucar-caceres, \& Wright, 2014) state that teleconferencing can provide social cues and behaviors, reducing barriers and challenges that have been associated with computer-mediated communication. They also associate team success with routine, frequent communication; reiteration of team objectives; and written summary and action plans as a follow-up to teleconferences. (Rimmington, Dickens, \& Pasquire, 2015) contend that the information and communication technology itself, as it is used to replace human-to-human interface, creates a distraction and leads to misinterpretation and miscommunication, which then negatively impacts project efficiency and effectiveness.

Change is inevitable. Tools and methods of project management change with technology and business processes. Synchronous and face-to-face meetings are replaced or augmented with asynchronous meetings, conference calls, or other electronic meeting media. Message and document delivery may change from snail mail and fax to an internetbased delivery software. Document collaboration may evolve from single-person editing software to on-line groupediting software. Data storage may migrate from in-house to cloud-based sites. Business processes may evolve from functional structures to integrated enterprise systems. However, there are core principles that defy the winds of change. Behaviors, ethics, and communication protocols, among others, remain key elements of effective project management. 


\section{ISSUES AND APPLICATIONS}

Project managers often occupy a unique position within an organization. In addition to managing a project team, these managers may serve as liaison between company leaders, vendors, stakeholders, special interest groups, and numerous other interested or involved parties. They may supervise both permanent members of a department and temporarily attached members from other functional and/or technical support departments as well as freelance employees who may be unfamiliar with procedures and processes. Team members from other departments are answerable to two supervisors: the project manager and a functional supervisor; an arrangement often causing tension and a sense of divided loyalty. So, the breadth of responsibility of the project manager provides unique and vastly divergent interpersonal communication challenges (Johansen \& Gillard, 2005).

Ironically, words themselves can be a barrier to effective communication. Some words invite interpretation: what is a modest gain, or an acceptable behavior, or a smart decision, or a good proposal? Some, like euphemisms, can be puzzling: what is the job of a maintenance engineer; when is an individual chronologically or mentally challenged? Other words and phrases are perception-based: one's perception dictates interpretation. Is the cup half-full or halfempty? Additionally, jargon (words unique to a profession) is often confusing to an individual outside the profession; and unfortunately, it is often the case that when an individual is asked, "do you understand", he or she will respond, "yes", but be thinking, "no, but I'm tired of looking stupid"! (Johansen \& Gillard, 2005)

The project manager will achieve clearer communication by choosing concrete words: words that convey specific meaning (a measurable limit or a specific behavior, for example) and words that are familiar and on the receiver's knowledge level. That is not an easy task. Jobs need to be done to keep the project on track; but the project manager needs to be aware that more time could be lost by miscommunication than by taking the time to consider the audience and to choose appropriate words to convey accurate meaning. It is helpful to state and restate important points, to acknowledge expressions and gestures of understanding, and to request a recap from the listener, especially when the chances of misunderstanding seem particularly high (Johansen \& Gillard, 2005).

Be aware of body language cues, too; your own as well as others. Standing with hands on hips is often interpreted as displaying anger or irritation; leaning forward while sitting as interest and attentiveness; shoving one's hands in one's pockets as nervousness; standing straight with hands at one's side as assertive and self-confident; and short, single nods as intent listening, to mention but a few (Driver \& Van Aalst, 2006). But equally important, the project manager should recognize that the best communication can often be silence; therefore, never pass up an opportunity to keep your mouth shut. Never answer a question that has not been asked; and do not elaborate just to show how much you know.

It is important to remember that communication should flow in both directions. It is a two-way street. People often know a lot more than they are credited with knowing. Listen! To listen requires input from someone else. Sometimes that means requesting input. Too many people have worthwhile input that is never conveyed because of past experiences. Elicit responses! Get an opinion from every person at every meeting, which probably means asking open-ended questions. Let them talk or don't invite them. Ask yourself, however, how many meetings it takes to equal one man-hour of productive work. Meetings should be used sparingly (like garlic). Use them for creating solutions for sticky problems. Use them to validate or modify strategy. Do not use them to "get the word out" (publish a newsletter instead).

Remember that you are part of a team. Members of your team should all be owners of your project. Communicate daily with as many people as you can. It keeps them informed as well as keeping you in touch. Let them know that you appreciate their work. Face the hard issues immediately. Ask for opinions/advice. Diplomacy is a requisite to cooperative productivity. It is prudent to note, then, that the location of an exchange can place an individual in an uncomfortable position or at a psychological disadvantage, creating communication disorder (Johansen, 2005). So go to their office (preferably physical, but virtual if necessary) to ask for help. The next time they will come to you. When your team is located in a central area (co-located), consider that if you hibernate at your desk, you will probably be perceived as not managing your program (even though you may be doing "paperwork" about your program). Your people need to feel important. See them on their home turf when possible. (Reprimand on your turf). It is amazing what you will pick up while you are wandering around. One face-to-face--even a teleconference- 
-is worth a thousand emails or phone calls. To emphasize, don't just sit or stand there, do something! If you just want to watch, buy a ticket. Teach your people to be action oriented (write a letter to ..., fix that by ..., call ..., go see ...). If your communications with them are working, they will know what to do. If they mess up, back them up.

Some individuals are reluctant to deliver bad news; however, the project manager should be the first to deliver bad news (as well as good news). If someone higher up the food chain hears the bad news from another source, the project manager will lose their trust. And if the project manager is perceived as being untrustworthy, it will probably extend into other areas, like dis/honesty. Thus, be honest in everything you say, write, and do. You will always get caught in a lie (eventually), and if you are perceived as a deceptive person, you are finished as a project manager. Conversely, ignorance is forgiven regularly. "I don't know" is always acceptable.

The more knowledgeable a project manager is about the business processes and environment for and in which the project is being developed, the more probable it is that the project manager will be successful. Therefore, you, as the project manager, should know more about the project than anyone else. You should never be challenged on the facts of your project; however, if you are challenged, "reseat" the challenger as gently as possible. But when decisions of your subordinates are challenged, as champion of your project, you should vigorously defend them. Maintaining absolute control of your project is an essential principle for project managers. If the project manager does not maintain control, someone else will. Only you, the project manager, should decide what is best for your project (that is why you are the project manager).

Being knowledgeable and maintaining control bleeds into knowing the unwritten "rules of the game". For example, insist on having all directions in writing. Control who may direct you via your contract or other written directives. Learn to discriminate direction from suggestion. When in doubt, write a memo "for the record". Ask for something in every brief you give. It may just be for support of your position. It may be for more people, time, or money (ask for money in a pre-brief first). But remember to ask only for something the receiver is empowered to give you.

Be (ummm...) decisive. Become known as a decision maker (that's what you are being paid for). Once you make a decision, do not reopen discussion unless something has changed. The common belief that forgiveness is easier to obtain than permission is applicable here. If you feel that an action is proper and correct for the project, then go ahead. Be certain you can justify your actions to yourself. Is the action in the best interest of your customer? Document your actions in a memo "for the record" and let your boss know. But recognize that no directive, regulation, or policy justifies a dumb decision. If it doesn't feel right, don't do it. Do not hide behind uninformed guidance. Go as high as you must to turn around bad direction.

Projects typically operate within a pre-defined budget. However, there is almost always need for a little extra here and there. It would therefore behoove the project manager to make a friend of the "money guy." He could bring your project to its knees. Ask for his advice on funding plans (if he owns it, he may not decrement it). Create as robust a project as you can afford. Embrace and apply standards and specifications, recognizing that when tailored properly, they do not add cost. Rather, they provide a logical and coherent method by which to approach the project design process. They ensure that all operational and environmental aspects of the project are addressed. Use discretion, however, and if they are clearly "overkill," ignore them or severely tailor them.

When your project involves a contractor or other outside stakeholder, treat him with respect. Cooperate with him as much as possible. You need him as much as he needs you. Believe that he has your best interest at heart until he proves otherwise. Remind him often that you are the customer. Be open with what you are considering so he can help (within the limits of the contract, Federal Acquisition Regulations, or other agreement documentation). Always try for the win-win solution. But bear in mind that contractors, attorneys, etc. are on your staff; you are not on theirs. If you frequently hear, "You can't do that...," replace them (if it is in your power to do so). Teach them to figure out how to do it. If the problem is beyond their experience, have them seek outside help. Broaden their horizons.

Consider that if things are running smoothly in your project, stand by! It is either a holiday or you are out of touch. Use the time to revisit your vision of the project. Talk to your customer to verify your own understanding of his needs. Seize the opportunity to improve the project. 


\section{SUMMARY}

Technology will always evolve and change the methods by which projects are completed. Projects themselves will change in nature and scope. But the human factors do not change. Ethical behavior, consideration of others, principles of communication, and a drive for knowledge and excellence are but a few examples of those invariable elements. Learning and practicing ways to optimize human interaction, to build trust and confidence, and to effectively communicate with project team members, internal and external stakeholders, and individuals in positions of authority will lead to more efficient and effective project development.

\section{AUTHOR BIOGRAPHY}

Sharlett Gillard is a Professor of Computer Information Systems at the University of Southern Indiana. Throughout her career she has been interested in numerous, diverse education and management issues, which has led to investigation of and collaboration with professionals in various educational disciplines and business arenas.

\section{REFERENCES}

Driver, J., \& Van Aalst, M. (2001). You say more than you think. New York, NY: Three Rivers Press.

Henderson, L. S, \& Stackman, R. W. (2010). An exploratory study of gender in project management: interrelationships with role, location, technology, and project cost. Project Management Journal, 41(5), 37-55.

Johansen, J. \& Gillard, S. (2005). Information resources project management communication: personal and environmental barriers. Journal of Information Science, 31(2), 91-98.

Kerzner, H. (2001/2009). Project management: A systems approach to planning, scheduling, and controlling, New York, NY, Hoboken, NJ: John Wiley \& Sons.

Morgan, L., Paucar-caceres, A., \& Wright, G. (2014). Leading effective global virtual teams: the consequences of methods of communication. Systemic Practice and Action Research, 27(6), 607-624.

Rimmington, A., Dickens, G., \& Pasquire, C. (2015). Impact of information and communication technology (ICT) on construction projects. Organization, Technology and Management in Construction: An International Journal, 7(3), 1367-1382.

Ziek, P., \& Anderson, J. D. (2015). Communication, dialogue and project management. International Journal of Managing Projects in Business, 8(4), 788-803. 